\title{
Recent experience on atrial septal defect device closure at Shahid Gangalal National Heart Centre, Kathmandu, Nepal
}

\author{
Chandra Mani Adhikari, Manish Shrestha, Amrit Bogati, Sachin Dhungel, Kiran Acharya, Urmila Shakya, \\ Poonam Sharma, Shilpa Aryal, Jagat Adhikari, Rabi Malla
}

\author{
Corresponding Author: Chandra Mani Adhikari \\ Department of Cardiology, Shahid Gangalal National Heart Centre Kathmandu, Nepal \\ Email: topjhap@gmail.com
}

Cite this article as: Adhikari C M, Shrestha M, Bogati A, et al. Recent experience on ASD device closure at Shahid Gangalal National Heart Centre, Kathmandu, Nepal. Nepalese Heart Journal 2019; Vol 16(1), 11-13

Received date: 25 th February 2019

Accepted date: 2nd April 2019

\section{Abstract}

\begin{abstract}
Background and Aims: Atrial septal defect (ASD) device closure has been accepted worldwide as an alternative to surgical closure with the excellent results. This interventional, non-surgical technique plays an important role in the treatment of ASD. This audit aims to report our experience of ASD device closure in our centre.
\end{abstract}

Methods: This cross sectional study was conducted at Shahid Gangalal National Heart Centre, Kathmandu, Nepal. All patients who were attempted for ASD device closure from February 2016 to January 2018 were included. ASD size, device size, procedural approach, and device implantation success rates were retrospectively analyzed from our hospital records.

Result: During the study period, 566 cases were attempted for device closure. Among them device was successfully implanted in 557(98.4\% of cases). In nine cases ASD device could not be implanted. Among the 557 successful cases, $401(71.9 \%)$ were female. Age ranged from 5 to 72 years with the mean of 30.9 years. In five patients, transcatheter closure cases, was done under general anesthesia with the guidance of transesophgeal echocardiogram. In all other patients, device closure was done in local anesthesia under transthoracic echocardiography guidance. ASD size ranged from $7 \mathrm{~mm}$ to $37 \mathrm{~mm}$ with the mean of $20.8 \mathrm{~mm}$. ASD device ranged from 8 to $42 \mathrm{~mm}$ with the mean of $26.5 \mathrm{~mm}$. Four different devices were used with the Amplatzer septal occluder used in 527 (94.6\%) patients, hyperion( Comed) device in $10(1.7 \%)$ patients, Memopart (Lepu) device in $19(3.4 \%)$ patients and Cera (Life tech) device in $1(0.1 \%)$ patients.

Discussion: ASD device closure is a safe and effective procedure.

Keywords: Atrial Septal Defect; Device Closure; Septal occluder

DOI: https://doi.org/10.3126/njh.v16i1.23891

\section{Introduction}

Atrial septal defect (ASD) is a common congenital heart defect, with an estimated birth prevalence of 1.6 per 1000 live births. ${ }^{1}$ Although recognized as a benign disease, if left untreated can contribute to a significant morbidity and mortality. ${ }^{2}$ For many decades, surgical intervention for ASD has been accepted as the standard treatment with excellent outcomes. However, surgical closure is associated with morbidity and thoracotomy scars. $^{3}$

ASD device closure is well-recognized mode of treatment for ostium secundun ASD all over the world. It is a preferred treatment option to surgical closure. ASD device closure procedure is safe, with little complication and short hospital stay in comparison to surgical closure. ${ }^{4,5}$ The aim of this audit is to share our experience of ASD device closure in recent two years in our center.

\section{Methods}

This cross sectional audit was conducted at Shahid Gangalal National Heart Centre, Kathmandu, Nepal from February 2016 to January 2018. All patients who were attempted for ASD device closure were included. All patients were evaluated in detail by 2-D echocardiography and transesophageal echocardiography (TEE) to assess the suitability for device closure before the procedure. Secundum ASD with significant left to right shunt evident by right ventricular overload were considered for device closure. ASD other than secundum type, associated cardiac anomaly, severe pulmonary hypertension with di-directional or right to left shunt were excluded. TEE was done to access the rims. All rims should be present $(\geq 5 \mathrm{~mm})$ except aortic rim. ASD of more than $35 \mathrm{~mm}$ in size were sent for surgery. Size of the device was decided by TEE in adults. In children, transthoracic echocardiography (TTE) was used to decide about the suitability of device closure. All patients were admitted on the same day of procedure and informed consent was taken. During the procedure, JR catheter with J tip terumo was crossed across ASD and parked in pulmonary vein. A super stiff exchange wire was parked in left/ right pulmonary vein depending upon the technique for device deployment. Then a specified delivery sheath was introduced and the device was loaded into it with a loader. Based upon the anatomy, conventional device deployment technique, right upper pulmonary vein technique, left upper pulmonary vein technique, balloon assisted technique or catheter assisted technique were

@Nepalese Heart Journal. Nepalese Heart Journal retains copyright and work is simultaneously licensed under Creative Commons Attribution License CC - BY 4.0 that allows others to share the work with an acknowledgement of the work's authorship and initial publication in this journal. 
used for device deployment. A continuous monitoring was done during the deployment of device with $2 \mathrm{D}$ echocardiography and fluoroscopy. After deployment either transthoracic or transoesophageal echocardiography was done depending on acoustic window to check for device position, residual leak, obstruction to flow and valve function. After release of device, 2-D echocardiography was performed to ensure for satisfactory closure of the defect. All patients were given I. V Heparin at 100 units $/ \mathrm{kg}$. First dose of antibiotic was given before the procedure followed by two more doses of antibiotics after the procedure. A repeat 2-D echocardiography was performed on next day before discharge. ASD size, device type and size, procedural characteristics and acute outcomes during device closure were retrospectively recorded from the hospital records.

\section{Result}

During the study period, 566 cases were attempted for device closure. In nine cases device implantation was not done. In three cases device was not implanted due to development of pericardial effusion during the procedure. Pericardiocentesis was done successfully at catherization lab in two cases, while one was managed surgically but patient died next day of surgery. One case developed pericardial effusion three hours after the procedure and underwent pericardiocentesis for tamponade but developed hypoxic cerebral injury. In six cases device was not implanted due to instability of the device.

Device implantation was successfully done in 557(98.4\%) patients. Among the 557 successful cases 401 (71.9\%) were female. Age ranged from 5 to 72 years with the mean of 30.9 years. Most of the cases were in the age group of 15-49 years as shown in table 1 . In five patients transcatheter closure was done under general anesthesia. In seven patients procedure was done under transesophgeal echocardiogram guidance. In all other cases procedure was done under local anesthesia and was assisted with transthoracic echocardiogram. In children local anesthesia along with intravenous anesthesia was used during the procedure. ASD size ranged from $7 \mathrm{~mm}$ to $37 \mathrm{~mm}$ in size with the mean of $20.8 \mathrm{~mm}$. ASD device size ranged from 8 to $42 \mathrm{~mm}$ with the mean of $26.5 \mathrm{~mm}$. Successful device closure of ASD with situs inversus totalis and dextrocardia was done in one case. One patient underwent ASD closure along with percutaneous coronary intervention with stent to RCA. Four different devices were used which includes Amplatzer septal occluder in 527 (94.6\%) patients, hyperion ( Comed) device in 10 (1.7\%) patients, Memopart (Lepu) device in $19(3.4 \%)$ patients and Cera (Life tech) device in $1(0.1 \%)$ patient as shown in table 2 . There were two patients with two defects that were successfully closed with a single device. Mean hospital stay after the procedure was 1.2 days. Among the 557 successful cases, two patients had a residual leak of $2 \mathrm{~mm}$. Device embolized to right pulmonary artery during the procedure in one patient. Embolized device was successfully retrieved with a goose neck snare. Device closure with another device was successfully done.

Table 1 Patients as per age group

\begin{tabular}{|l|l|l|}
\hline & $\mathrm{N}$ & $\%$ \\
\hline Age $\leq 15$ years & 110 & 19.7 \\
\hline $15-49$ years & 376 & 67.5 \\
\hline$\geq 50$ years & 71 & 12.8 \\
\hline
\end{tabular}

Table 2 Types of ASD devices

\begin{tabular}{|l|l|l|}
\hline Types of devices & $\mathrm{N}$ & $\%$ \\
\hline $\begin{array}{l}\text { Amplatzer septal } \\
\text { occluder }\end{array}$ & 527 & 94.6 \\
\hline $\begin{array}{l}\text { Hyperion ( Comed) } \\
\text { device }\end{array}$ & 10 & 1.7 \\
\hline Memopart (Lepu) & 19 & 3.4 \\
\hline Cera (Life tech) & 1 & 0.1 \\
\hline
\end{tabular}

\section{Discussion}

ASD device closure has become a method of choice in most of the patients with secundum ASD. ${ }^{6}$ It is not only safe but also effective. In this audit we shared our two-year experience of ASD device closure in the National Heart Centre. The major advantages of percutaneous closure of ASD are the absence of thoracotomy, open heart surgery and admission in an intensive care unit. Thus avoiding subsequent surgical scar and postoperative pain. ${ }^{4,6,7}$ The other advantages are less psychological impact, shorter hospital stay, and less need for blood transfusion. ${ }^{5,7}$ The absence of myocardial scar may decrease the incidence of incisional dysrhythmias. ${ }^{7}$ Device implantation success rate of $98.4 \%$ is comparable to studies around the world where the success rate of device closure remained between 94$99 \%$. $2,5,9,10,11,12,13,14$

Two patients had residual leak of $2 \mathrm{~mm}$ in our series. Successful closure implies complete closure with residual leak of $<1$ to 2 $\mathrm{mm}$ and stable device position. ${ }^{15}$ The Boutin classification for residual shunt is as follows: mild $1-2 \mathrm{~mm}$; moderate $2-4 \mathrm{~mm}$ and large $>4 \mathrm{~mm} .{ }^{16}$ Mild-moderate shunts may improve or disappear with endothelialization of the device..$^{15}$

Amplatzer septal occluder is the most commonly used device in our centre. It is the most extensively studied device worldwide. It is the first device to receive full approval for clinical use in patients with ASD by United States Food and Drug Administration. ${ }^{17}$ Device was implanted with TTE guidance in most of our cases. Device closure of ASD guided by TTE is sufficient and safe, in patients with good imaging windows. . $^{18,19,20}$

Device embolization occurred in one patient in this study. In many studies, ${ }^{21,22,23}$ device embolization/malposition is the most common major complication. Proper size selection and meticulous imaging before the release of device can help in preventing this complication. Four patients developed pericardial effusion, three during the procedure while other 3 hours after the procedure. Cardiac perforation is a serious complication reported in many literatures. ${ }^{24,25}$ Perforation during procedure are caused by the wires, and catheter maneuvers.

In two patients two ASDs were closed with a single device. In both cases ASD were separated by $<7 \mathrm{~mm}$. Hu et al. ${ }^{26}$ reported the safety and efficacy of closure of multiple defects by a single device, with no difference from dual occluders, even though the risk of residual shunting was greater with dual occluders. If two ASD are separated by $<7 \mathrm{~mm}$, they can be closed with a single device. However, many studies have recommended closure of multiple defects with a distance $>7 \mathrm{~mm}$ with two devices. ${ }^{27}$

Our study had some limitations which includes retrospective study with no long term follow up. 


\section{Conclusion}

ASD device closure is safe and effective. It is a good alternative to surgery in ASD which are suitable for device closure.

\section{References}

1. Van der Linde D, Konings EEM.Slager MA, et al. Birth Prevalence of congenital heart disease worldwide: a systemic review and meta-analysis.J Am Coll Cardiol 2011;58(21):2241.

https://doi.org/10.1016/j.jacc.2011.08.025

2 Ali S H, Sisi A E, Raafat D M, et al. Short-term outcomes of transcatheter closure of secundum atrial septal defect in children and adolescents: An experience of two centers in Upper Egypt, J Saudi Heart Assoc 2017;30(1) 14-20. http://dx.doi.org/10.1016/j.jsha.2017.04.004

3 Galal MO, Wobst A, Halees Z, et al. Peri-operative complications following surgical closure of atrial septal defects type II in 232 patients: a baseline study. Eur Heart J 1994;15: 1381-4.

https://doi.org/10.1093/oxfordjournals.eurheartj.a060398

4 Du ZD, Hijazi ZM, Kleinman CS, et al. Comparison between transcatheter and surgical closure of secundum atrial septal defect in children and adults: results of a multicenter nonrandomized trial. J AmColl Cardiol 2002; :1836-44. https://doi.org/10.1016/S0735-1097(02)01862-4

5 Suchon E, Pieculewicz M, Tracz W, et al. Transcatheter closure as an alternative and equivalent method to the surgical treatment of atrial septal defect in adults: comparison of early and late result. Med Sci Monit 2009;15(12):CR612-7.

6. Feinstein JA, Gomes AS. Indications for cardiac catheterization and intervention in pediatric cardiac disease: a scientific statement from the American Heart Association. Circulation 2011;123: 2607-52. https://doi.org/10.1161/CIR.0b013e31821b1f10

7. Lee $\mathrm{CH}$, Kwok OH, Fan K, et al. Transcatheter closure of atrial septal defect using Amplatzer septal occluder in Chinese adult. Cathet Cardiovasc 2001;52(3):373-7. https://doi.org/10.1002/ccd.1184

8. Butera G, Rosa GD, Chesa M, et al. Transcatheter closure of atrial septal defect in young children. J Am Coll Cardiol 2003;42(2):241-5.

https://doi.org/10.1016/S0735-1097(03)00589-8

9. Sukman T P, Mulyadi M D, Nikmah S I, et.al.Transcatheter Closure of Atrial Septal Defects in a Center with Limited Resources: Outcomes and Short Term Follow-Up Iran J Pediatr. 2015; 25(6): e3906.

https://doi.org/10.5812/ijp.3906

10 Mohammad Ali Ostovan, Javad Kojuri, Pooyan Dehghani, et.al. Device closure in adults with atrial septal defect in Shiraz, a single center registry. J Cardiovasc Thorac Res, 2016, 8(1), 40-42. https://doi.org/10.15171/jcvtr.2016.07

11 Nadeem Sadiq, Maad Ullah, Amjad Mahmood, et.al. Transcatheter device closure of secundum asd - a 10 years experience - a single centre study. Pak Heart J 2015;48(3): $158-162$.

12 Fischer G, Stieh J, Uebing A, et al. Experience with transcatheter closure of atrial septal defects using the Amplatzer septal occluder: a single centre study in 236 consecutive patients. Heart 2003; 39: 1836-44. https://doi.org/10.1136/heart.89.2.199

13 Sadiq M, Kazmi T, Rehman AU, et al. Device closure of atrial septal defect: medium-term outcome with special reference to complications. Cardiol Young 2012; 22:71-8. https://doi.org/10.1017/S104795111100093X

14 Behjati M, Mirhosseini SJ, Hosseini SH, et al. Transcatheter
Closure of Atrial Septal Defect with Amplatzer Device in Children and Adolescents: Short and Midterm results; an Iranian Experience. Iranian Journal of Pediatrics, 2011; 21(2): 166-172.

15 Bissessor N. Current perspectives in percutaneous atrial septal defect closure devices. Medical Devices: Evidence and Research 2015;8: 297-303.

https://doi.org/10.2147/MDER.S49368

16 Boutin C, Musewe N N, Smallhorn J F, et al. Echocardiographic follow-up of atrial septal defect after catheter closure by double-umbrella device. Circulation 1993;88(2) 621-27. https://doi.org/10.1161/01.CIR.88.2.621

17 Lin MC, Fu YC, Jan SL, et al. Transcatheter closure of secundum atrial septal defect using the Amplatzer septal occluder: initial of a single medical centre in Taiwan. Acta Paediatr Taiwan 2005;46(1):17-23.

18 Li GS, Kong GM, Ji QS, et al. Reliability of transthoracic echocardiography in estimating the size of Amplatzer septal occluder and guiding percutaneous closure of atrial septal defects. Chin Med J (Engl). 2008;121(11):973-6. https://doi.org/10.1097/00029330-200806010-00003

19 Li GS, Kong GM, Wang YL, et al. Safety and efficacy of transcatheter closure of atrial septal defects guided by transthoracic echocardiography: a prospective study from two Chinese Medical Centers. Ultrasound Med Biol 2009; 35(1):58-64.

https://doi.org/10.1016/j.ultrasmedbio.2008.06.008

20 Zaqout M, Suys B, De Wilde H, et al. Transthoracic echocardiography guidance of transcatheter atrial septal defect closure in children. Pediatr Cardiol 2009;30(7):9924. https://doi.org/10.1007/s00246-009-9456-8

21 Celiker A, Ozkutlu S, Karago ZT, et al. Transcatheter closure of interatrial communications with Amplatzer device: results, unfulfilled attempts and special considerations in children and adolescents. Anadolu Kardiol Dreg 2005;5(3):159-64.

22 Wilson NJ, Smith J, Prommete B, et al. Transcatheter closure of secundum atrial septal defects with the Amplatzer septal occluder in adults and children, follow up closure rates, degree of mitral regurgitation and evaluation of arrhythmias. Hurt Lung Circ 2008;17(4):318-24. https://doi.org/10.1016/j.hlc.2007.10.013

23 Spence MS, Qureshi SA. Complication of transcatheter closure of atrial septal defect. Heart 2005;91(12):1512-4. https://doi.org/10.1136/hrt.2004.057562

24 Divekar A, Gaamangwe T, Shaikh N, et al. Cardiac perforation after device closure of atrial septal defects with Amplatzer septal occluder. J Am Coll Cardiol 2005; 45: 1203-1208. https://doi.org/10.1016/j.jacc.2004.12.072

25 Amiz Z, Hijazi ZM, Bass JL, et al. Erosion of Amplatzer Septal Occluder device after closure of secundum Atrial Septal Defect: Review of registry of complications and recommendation to minimize future risk. Catheter Cardiovasc Interv 2004;63(4):496-502 https://doi.org/10.1002/ccd.20211

26 Hu Z, Zhang Y, Zhang T, et al. Comparison of the effectiveness and safety of single versus dual occluders for the closure of multiple atrial septal defects. J Invasive Cardiol 2015;27: E90-7.

27 Bramlet MT, Hoyer MH. Single pediatric center experience with multiple device implantation for complex secundum atrial septal defects. Catheter Cardiovasc Interv 2008;72:531-7. https://doi.org/10.1002/ccd.21668 